\title{
The Fundamentals to Minimize the Culture Failure in Hematological Malignancies
}

\section{Sumithra Martinovic1 ${ }^{*}$, Bhanu Prakash Lalkota², Mithua Ghosh1, Belagutty Jayappa Srinivasa², Prasanna Kumari ${ }^{1}$}

\author{
${ }^{1}$ Department of Cytogenetics, R and D, Healthcare Global Enterprises Ltd., Bangalore, India \\ ${ }^{2}$ Department of Medical Oncology, Healthcare Global Enterprises Ltd., Bangalore, India \\ Email: *sumithragenetics@gmail.com
}

How to cite this paper: Martinovic, S., Lalkota, B.P., Ghosh, M., Srinivasa, B.J. and Kumari, P. (2020) The Fundamentals to Minimize the Culture Failure in Hematological Malignancies. Open Access Library Journal, 7: e6760.

https://doi.org/10.4236/oalib.1106760

Received: August 29, 2020

Accepted: September 19, 2020

Published: September 22, 2020

Copyright () 2020 by author(s) and Open Access Library Inc.

This work is licensed under the Creative Commons Attribution International License (CC BY 4.0).

http://creativecommons.org/licenses/by/4.0/

\begin{abstract}
Cytogenetics plays a major role in Cancer studies, as some abnormalities aid in the correct categorizing of leukemia and lymphomas, and additionally provides important prognostic information. Though every laboratory follows SOP's, there is always a chance of culture failure. We processed and analyzed 36 BMA (Bone marrow aspirate) and 31 PB samples (Peripheral blood) with referral reasons: Acute lymphoblastic leukemia (ALL) $n=37$, Chronic lymphocytic leukemia (CLL) $\mathrm{n}=7$, Acute myeloid leukemia (AML) $\mathrm{n}=5$, Chronic myeloid leukemia (CML) $n=3$, Myelodysplastic syndrome (MDS) $\mathrm{n}=1$, Pancytopenia $\mathrm{n}=2$, Aplastic anemia $\mathrm{n}=2$, and others $\mathrm{n}=10$. The culture failure rate was $13.4 \%$. Factors affecting the culture other than the technical errors are aged samples, low, high cell count and impoverished metaphases (less than 10 metaphases are not considered). Viability decreases based on the age of the sample. Successful karyotyping can be achieved, when the BMA or PB samples arrive and are cultured within 24 hours.
\end{abstract}

\section{Subject Areas}

Genetics

\section{Keywords}

Cytogenetics, Culture Failure, BMA, PB, Karyotype, Hematological

Malignancies, Low Cell Count, High Cell Count

\section{Introduction}

Karyotyping is an important element in cancer cytogenetics as it significantly helps in treatment of patient with targeted drug therapy. Mutual association of 
clinico-cytogenetic studies made easier to classify hematological malignancy and manycytogenetic abnormalities, which provide pivotal prognostic information [1]. Conventional Cytogenetics still remains a requisite test, as it can detect numerical and structural abnormalities. Cytogenetic studies for hematological malignancies are complex. Multiple slides should be analyzed to get good metaphases. The described rate of culture failure in hematological malignancy is $10 \%$ [2]. Karyotyping is not locus specific like FISH, and hence can detect additional abnormalities, but may miss minor deletion in the chromosomes as it can detect only abnormalities larger than $5 \mathrm{Mb}$ [3]. Fluorescent in situ hybridization (FISH) is a molecular cytogenetic technique that is frequently used along with cytogenetics. It can be performed on dividing cells and non dividing interphase cells [4] [5]. Poor quality metaphases and banding, scanty metaphases, aged sample, technical error, ph change in the media, insufficient sample, clotted sample, low and high cell count constitute failure of culture. Bone Marrow aspirate (BMA) is preferable (where the blood cells are produced) than Peripheral Blood (PB). PB is accepted when it has more than $25 \%$ blast cells. This is a single centre study, aimed to show the significance of sample transit time and other factors that should be considered from the time of sampling to banding.

\section{Material and Methods}

The present study was conducted at Cytogenetics department, HCG Hospitals, Bengaluru, India. We analysed a total of 499 cases from 2017 to 2018, received samples from different part of India as well. Unfortunately, some samples reached the laboratory after 24 to 72 hours. When there was no other possibility of getting repeat sample, aged Bone marrow aspirate sample were processed as per Clinicians request. Depending on the cell count ( 1 - 10 million cells per culture) sample should be processed in less than 24 hours and setting up of multiple culture is a must procedure [6]. BMA and PB samples were processed and cultured for direct, 24 and 48 hours (sometimes 72 hours to have 3 different cultures) without PHA in $10 \mathrm{ml}$ of RPMI media supplemented with 10 percent FBS, harvested, banded and analyzed respectively [6]. Out of 499 samples, 36 BMA and 31 PB failed to produce metaphases or produced few metaphases for Karyotyping. Previous studies suggest that $\mathrm{PB}$ has higher rate of culture failure than the BMA [6], in our study BMA outnumbered PB samples.

\section{Results}

From 67 failed cultures, 35 (52.2\%) samples were from external centers. The median age of the patients were 46 years $(3-86)$ and 39 of them were male (58.2\%). Failed cultures had referral reasons like ALL-37 (55.2\%), CLL-7 (10.4\%), AML-5 (7.4\%), CML (4.4\%), MDS-1 (1.4\%), Pancytopenia-2 (2.9\%), Aplastic anemia-2 (2.9\%) and others- 10 (14.9\%). The time from sample received to sample processing was: $<24 \mathrm{~h}-32,>24 \mathrm{~h}-20,>48 \mathrm{~h}-3,>72 \mathrm{~h}-12.3$ BMA had low cell count, 7 BMA and 9 PB sample had high cell count. Culture failed to yield 
metaphases in most of this high and low cell count cases.

20 metaphases is the standard number for analysis. Most of the samples received were from different centers, transit time was between more than 24 hours to less than 96 hours. Delayed 12 samples and 2 BMA samples with low volume resulted in yielding no metaphases. 8 (5 BMA and 3 PB) Samples with the normal count yielded poor quality and few metaphases (less than 10 metaphases will be considered sub optimal). Other samples failed to produce metaphase in all 3 cultures. There was no much difference in any of the multiple cultures. High rate of culture failure is seen in delayed and sample processed after 24 hours to 72 hours. To minimize the culture failure rate, it is important to maintain the transit time, to receive and process the sample within 24 hours [6].

11 BMA and 2 PB samples with very low cell counts were rejected, which did not come under standard norms and informed to the respective clinicians.

\section{Discussion}

Failure of Cytogenetics studies is disappointing as it is important in diagnosis and for the targeted therapy treatment of the patient. This study may help the cytogeneticists to understand the importance of time which may adversely affects the culture. Table 1 shows detailed failure rate in percentage.

According to the guidelines of Canadian collage of Medical Geneticists, failure rate should not exceed $10 \%$ [3]. Overall incidence of culture failure in our center is $13.4 \%$ which is not correlating with the Canadian collage guidelines.

BMA is notorious of producing low quality metaphases. 6 BMA and $2 \mathrm{~PB}$ (11.4\%) produced scanty metaphases, which led to failed karyotyping. Impoverished metaphases are hard to analyse, this may be due to technical error. Condensed chromosoms are the result of long exposure or adding high concentration of colcemid and long overlapping metaphases are due to low concentration [6]. Improper spreading of metaphases is due to hypotonic solution or substandard spreading techniques. Aging of slide is a vital step, as it affects banding and is recommended to age the slide in room temperature for a week, in the oven for an hour at 90 degrees or at 60 degrees overnight.

Table 1. Influential factors affecting cultures.

\begin{tabular}{|c|c|c|c|c|c|c|}
\hline & $\begin{array}{l}\text { Type of } \\
\text { sample }\end{array}$ & $\begin{array}{c}\text { Samples in } \\
\text { numbers }\end{array}$ & $\begin{array}{l}\text { Low cell } \\
\text { count }\end{array}$ & $\begin{array}{l}\text { High cell } \\
\text { count }\end{array}$ & $\begin{array}{l}\text { Scanty } \\
\text { metaphases } \\
\text { with poor } \\
\text { morphology }\end{array}$ & $\begin{array}{l}\text { Quantity } \\
\text { not } \\
\text { sufficient }\end{array}$ \\
\hline $\begin{array}{c}<24 \\
\text { hours }\end{array}$ & $\begin{array}{c}\text { BMA-22 } \\
\text { PB-10 }\end{array}$ & $32(47.7 \%)$ & $1(1.4 \%)$ & $11(16.4 \%)$ & $6(8.9 \%)$ & $1(1.4 \%)$ \\
\hline $\begin{array}{c}>24-48 \\
\text { hours }\end{array}$ & $\begin{array}{l}\text { BMA-9 } \\
\text { PB-14 }\end{array}$ & $23(34.3 \%)$ & $1(1.4 \%)$ & $5(7.4 \%)$ & $2(2.9 \%)$ & $1(1.4 \%)$ \\
\hline $\begin{array}{l}>72 \\
\text { hours }\end{array}$ & $\begin{array}{c}\text { BMA-7 } \\
\text { PB-5 }\end{array}$ & $12(17.9 \%)$ & - & - & - & - \\
\hline Total & 67 & 67 & $3(4.4 \%)$ & $16(23.8)$ & $8(11.9 \%)$ & $2(2.9 \%)$ \\
\hline
\end{tabular}


The other technical errors may be due to change in $\mathrm{pH}$ of media (which changes the colour to yellow) and if it is cloudy that might be due to contamination, which should be checked frequently. It is difficult to find the errors in reagents, If suspected or if the reagent is cloudy (contamination), discard and make a new reagent. Check for the shelf life of the chemicals. New media or serum should be checked for its working ability before processing the original samples.

Always samples should be collected in heparinized vacutainers, others should be rejected as it hamper the cells. It is recommended to transport the sample in transport media and to be processed and cultured within 24 hours for preserving the viable cells [6] [7] [8]. When the quantity of the sample is not sufficient, it should be cultured in $4-5 \mathrm{ml}$ of media, still if it does not fit to the standard norms then it should be rejected. We had $2.9 \%$ of low volume samples, which did not yield any metaphases.

Chances of success in karyotyping from aged sample are very rare, as it will affect the viablility of cells. 12 (17.9\%) samples were more than 72 hours old. Cellularity of sample in $1 \mathrm{~mL}$ should be $1 \times 10^{6} .4 .4 \%$ of the samples had low cell count, failed to produce dividing and enough viable cells. 16 samples $(23.8 \%)$ had high cell count, culture failure rate is more in high cell count sample than the low cell count sample, as majority of cells cannot divide and it will inhibit other cells that are capable of division. Less than 24 to 48 hours had low cellularity, high cellularity, scanty metaphases and low volume samples. In our study, ALL had high rate of failure than sample with other indications, this is due to high cellularity, usual tendency for the sample to clot during harvesting (which may hamper the quality of metaphases), and most of the ALL cases produce poor metaphases [6]. Routine temperature check in the incubator is must as increase or decrease in temperature will affect the cells. All equipments should be monitored to prevent malfunction.

However, FISH technique can be used when cytogenetic studies fail to yield result, which specifically binds to the labelled DNA [4]. One of the main advantage is it's capability to use non-dividing interphase cells as DNA targets [5] [6]. In contrast with the chromosomal banding technique, FISH cannot serve as a screening test in chromosomal rearrangements, as it can only detect known imbalances [9]. FISH may fail to detect small microdeletions smaller than $190 \mathrm{~kb}$, giving false negative results [10].

Cytogenetics still remains gold standard in identifying numerical and large chromosomal abnormalities. FISH can be used as complementary technique, than as competator with cytogenetics. Though previous studies mainly point towards samples cellularity and quality [3], for hematological malignancies it is important to maintain the transit time of the sample as it will have more number of viable cells, loosing these valuable cells may cost later resulting in failure of the sample. Every step from transportation to banding is sensitive so measures should be taken so that most of the errors can be avoided. Our study is based on small number of patient samples and $47.7 \%$ of the failed cultures were from 
more than 24 to 72 hours and above. Large study is required to confirm the same.

\section{Conclusion}

Some culture failure cannot be avoidable. Errors can occur at any point from initiation to staining, that should be investigated and recorded. Though many factors affect sample, failure of cultures can be minimized by taking strict measures in theinitial step (transportation and processing of samples in $>24$ hours) which plays crucial role in preserving the viable cells.

\section{Acknowledgements}

I extend my thanks to Djordje Martinovic, staffs of Cytogenetics department and HCG Hospital for their support.

\section{Conflicts of Interest}

The authors declared to have no conflicts of interest.

\section{References}

[1] Campo, E., Swerdlow, S.H., Harris, N.L., Pileri, S., Stein, H. and Jaffe, E.S. (2011) The 2008 WHO Classification of Lymphoid Neoplasms and beyond: Evolving Concepts and Practical Applications. Blood, The Journal of the American Society of Hematology, 117, 5019-5032. https://doi.org/10.1182/blood-2011-01-293050

[2] Dawson, A.J., McGowan-Jordan, J., Chernos, J., Xu, J., Lavoie, J., Wang, J.C., et al. (2011) Canadian College of Medical Geneticists Guidelines for the Indications, Analysis, and Reporting of Cancer Specimens. Current Oncology, 18, e250. https://doi.org/10.3747/co.v18i5.775

[3] Santos, M.F.M., Oliveira, F.C.A.C., Kishimoto, R.K., Borri, D., Santos, F.P.S., Campregher, P.V., et al. (2019) Pre-Analytical Parameters Associated with Unsuccessful Karyotyping in Myeloid Neoplasm: A Study of 421 Samples. Brazilian Journal of Medical and Biological Research, 52, No. 2. https://doi.org/10.1590/1414-431x20188194

[4] Medeiros, B.C., Othus, M., Estey, E.H., Fang, M. and Appelbaum, F.R. (2014) Unsuccessful Diagnostic Cytogenetic Analysis Is a Poor Prognostic Feature in Acute Myeloid Leukaemia. British Journal of Haematology, 164, 245-250.

https://doi.org/10.1111/bjh.12625

[5] Haferlach, C., Rieder, H., Lillington, D.M., Dastugue, N., Hagemeijer, A., Harbott, J., et al. (2007) Proposals for Standardized Protocols for Cytogenetic Analyses of Acute Leukemias, Chronic Lymphocytic Leukemia, Chronic Myeloid Leukemia, Chronic Myeloproliferative Disorders, and Myelodysplastic Syndromes. Genes, Chromosomes and Cancer, 46, 494-499. https://doi.org/10.1002/gcc.20433

[6] Swansbury, J. (2003) Cytogenetic Studies in Hematologic Malignancies. In Cancer Cytogenetics (pp. 9-22). New Jersey: Humana Press.

https://doi.org/10.1385/1-59259-363-1:009

[7] Mikhail, F.M., Heerema, N.A., Rao, K.W., Burnside, R.D., Cherry, A.M. and Cooley, L.D. (2016) Section E6. 1-6.4 of the ACMG Technical Standards and Guidelines: Chromosome Studies of Neoplastic Blood and Bone Marrow-Acquired Chromo- 
somal Abnormalities. Genetics in Medicine, 18, 635-642.

https://doi.org/10.1038/gim.2016.50

[8] Lozynskyy, R.Y., Lozynska, M.R., Hontar, Y.V., Huleyuk, N.L., Maslyak, Z.V. and Novak, V.L. (2016) Study of Cytogenetic Abnormalities in G-CSF Stimulated Peripheral Blood Cells and Non-Stimulated Bone Marrow Cells of Patients with Myelofibrosis. Experimental Oncology, 38, No. 1.

https://doi.org/10.31768/2312-8852.2016.38(1):40-44

[9] Speicher, M.R. and Carter, N.P. (2005) The New Cytogenetics: Blurring the Boundaries with Molecular Biology. Nature Reviews Genetics, 6, 782-792. https://doi.org/10.1038/nrg1692

[10] Savola, S., Nardi, F., Scotlandi, K., Picci, P. and Knuutila, S. (2007) Microdeletions in 9p21. 3 Induce False Negative Results in CDKN2A FISH Analysis of Ewing Sarcoma. Cytogenetic and Genome Research, 119, 21-26.

https://doi.org/10.1159/000109614 